\title{
Trends in healthy life expectancy in Hong Kong SAR 1996-2008
}

\author{
Karen Siu Lan Cheung • Paul Siu Fai Yip
}

Published online: 9 November 2010

(c) The Author(s) 2010. This article is published with open access at Springerlink.com

\begin{abstract}
Although Hong Kong has one of the best life expectancy (LE) records in the world, second only to Japan for women, we know very little about the changes in the health status of the older adult population. Our article aims to provide a better understanding of trends in both chronic morbidity and disability for older men and women. The authors compute chronic morbidity-free and disability-free life expectancy and the proportion of both in relation to total LE using the Sullivan method to examine whether Hong Kong older adults are experiencing a compression of morbidity and disability and whether there is any gender difference in relation to mortality and morbidity. The results of this study show that Hong Kong women tend to outlive Hong Kong men but are also more likely to suffer from a 'double disadvantage', namely more years of life with more chronic morbidity and disability. There has also been a significant expansion of chronic morbidity, as chronic morbidity-free life expectancy (CMFLE) decreased substantially for both genders from 1996 to 2008. Although disability-free life expectancy (DFLE) increased during this period, it increased at a slower pace compared to LE. The proportion of life without chronic morbidity also declined remarkably during these 12 years. Among the advanced ages, the proportion of remaining life in good
\end{abstract}

Communicated by Dorly J.H. Deeg.

The earlier version of this research article was presented at $21 \mathrm{st}$ REVES 2009: Reducing gaps in health expectancy, May 27-29, 2009 in Copenhagen, Denmark.

K. S. L. Cheung $(\varangle) \cdot$ P. S. F. Yip

Department of Social Work and Social Administration,

The University of Hong Kong, Hong Kong, China

e-mail: cslk@hku.hk health without disability has decreased since 1996, indicating a relative expansion of disability.

Keywords Healthy life expectancy · Chronic morbidity and disability · Gender gap · Hong Kong SAR

\section{Introduction}

Sixty years ago, in their studies of the Public Health Service in the Eastern Health District of Baltimore, Downes (1950) and Jackson (1950) noted that the mortality rate for men was higher than that for women, whereas the morbidity rate for women was considerably higher than that for men. They found that, in terms of sickness and the number of medical calls and cases of hospitalization related to chronic illnesses, the rates for women were much higher than those for men. Their observations not only documented a gender difference in relation to mortality and morbidity, but were also germane to Sanders' provocative article (Sanders 1964). In his article, Sanders argued that the earlier diagnosis of diseases and better patient care would delay serious incapacitation and prolong life and that this could increase the prevalence of diseases and impairments in the population. Similar to Sanders, Gruenberg (1977) put forward 'the failures of success' argument that people's lives are prolonged or saved by successful medical innovations and that the result of this is manifest in a larger number of 'unfit and frailer' survivors living longer and placing increasing burdens on society.

The recent falling mortality rates among older people and the continuing increase in life expectancy (LE) demonstrate that average individual lifetimes are considerably longer than they have ever been and that the shape of the survival curves has changed over time, moving closer 
towards becoming rectangular curves (Fries 1980; Kannisto 2001; Laslett 1995; Wilmoth and Horiuchi 1999). The conspicuous compression of mortality has been observed in many Western industrialized countries in the last two decades (Canudas-Romo 2008; Cheung and Robine 2007; Cheung et al. 2008, 2009; Kannisto 2001; Manton and Stallard 1996; Martel and Bourbeau 2003; Nusselder and Mackenbach 1996; Paccaud et al. 1998; Pelletier et al. 1997; Robine 2001; Robine et al. 2006; Rothenberg et al. 1991; Thatcher et al. 2010; Wilmoth and Horiuchi 1999) and in Hong Kong during the last decade (Cheung 2003; Cheung et al. 2005a, b), indicating that the majority of people are dying at an advanced age, such as in their late eighties or in their nineties. As old age and old people are both now commonplace in the entire Western and industrialized countries and regions, one of the most burning questions in the research on population ageing is whether this increase in LE is characterised by good health or by bad health and an ever-increasing accumulation of chronic diseases and disabilities. The relationship between the mortality level and the health status of a population still intrigues social scientists, demographers, gerontologists and population economists (Robine et al. 2009).

Since Sanders' and Gruenberg's propositions were promulgated, three theories on the disability-free and productive lives of old people were developed in the 1980s and 1990s. The operationalization of the relationship between mortality and different health domains in three scenarios-the compression of morbidity assuming that medical progress and healthy life styles can postpone the onset of health problems leading to a reduction in the cumulative life time with morbidity to a small part of the life expectancy (Fries 1980), the expansion of morbidity proposing that the same medical progress will increase the survival of the frail elderly people rather than a reduction in the morbidity incidence inducing the trade-off between longer life and worsening health (Kramer 1980; Verbrugge 1984; Olshansky et al. 1991) and the dynamic equilibrium theorizing that the increase in morbidity is offset by a decrease in the severity leading the proportion of life lived in good health more or less constant (Manton 1982) - has been widely discussed in the International Network on Health Expectancy REVES and used by other colleagues in the field (Brønnum-Hansen 2005; Crimmins and Saito 1993; Doblhammer and Kytir 2001; Jeune and BrønnumHansen 2008; Nusselder 2003; Nusselder et al. 2006; Perenboom 2004; Robine et al. 1987, 2008, 2009; Robine 2002; Robine and Mathers 1993; Robine and Michel 2004).

Several major health indicators, such as self-perceived health, chronic morbidity, co-morbidity and disability, are usually used to examine the health of a population and to determine the average number of years within a total LE, which are lived in a given state of health. According to the
International Classification of Functioning, Disability and Health (ICF) of the World Health Organization (WHO 2001), the term disability generally refers to activity limitations and participation restrictions. It is a generic term defined as the impact of disease or injury on the functioning of an individual and covers various situations, from rather common functional limitations to restrictions in daily activities and leading finally to dependency (Cambois et al. 2008). Six basic measures of the functional independence or dependence of patients in terms of bathing, dressing, going to toilet, transferring, continence and feeding were first developed and evaluated by Katz and his colleagues at the Benjamin Rose Hospital to specify the type of assistance that patients received (Katz et al. 1963; The Staff of the Benjamin Rose Hospital 1959, 1960, 1961, 1962). When the term disability relates to criteria other than those cited above, specific definitions of disability are usually provided (Robine et al. 2008).

Today, it is acknowledged in Europe and the U.S. that the various health dimensions may follow different trends over time (Robine 2006; Ahacic et al. 2007; Parker and Thorslund 2007). The most recent OECD study (Lafortune and Balestat 2007) reviewing national trends in activities in daily living (ADL) disability in people aged 65 and over in 12 OECD countries during the 1990s revealed conflicting results. Only 5 of the 12 countries studied (Denmark, Finland, Italy, the Netherlands and the U.S.) reported a decline in disability among older people. Three countries (Belgium, Japan and Sweden) reported an increasing disability rate and two countries (Australia and Canada) reported a stable rate. Surveys conducted in France and the United Kingdom revealed different trends in ADL disability (Lafortune and Balestat 2007). Overall, these results suggest that a decline in ADL disability may not be universal.

Regarding East Asia, a comparative study by Ofstedal et al. (2004) showed that healthy LE declined steadily with age in five Asian countries (Indonesia, the Philippines, Singapore, Taiwan and Thailand) and remained fairly stable in China when self-assessed health data from national surveys in the mid-1990s were used as a measure. They found that women generally lived longer, but less healthy lives than men. However, a recent article by Liu et al. (2009) showed that trends in disability-free life expectancy (DFLE), the severity of disability and the delayed onset of disability provide evidence for the compression of morbidity among the oldest-old (i.e. aged $75+$ ) in China. In Japan, a recent study revealed that an expansion of morbidity occurred between 1995 and 2004 and that the increases in LE during this period occurred in years of poor self-rated health (Yong and Saito 2009). These results differ from those of another study (Schoeni et al. 2006) which, using functioning and disability as health measures, 
indicated that there was an improvement in the health among the Japanese during the period 1993-2002.

Although Hong Kong SAR has been part of Mainland China since the handover of sovereignty in 1997, its medical and health care system is considerably different from that of the Mainland. In Hong Kong, improvements in research techniques and an enthusiasm for collecting data on illness and disability have not resulted in a full understanding of whether Hong Kong people are living longer in good health, and whether there are any gender differences in relation to chronic diseases and disability. Three local studies have been conducted in the past few years (Cheung and Tu 2002; Chou and Leung 2008; Law and Yip 2003), but their results suggest contrasting trends in disability and morbidity. Based on the Central Registry Rehabilitation data on disability and the Sullivan-based prevalence method, Cheung and Tu (2002) showed that, between 1991-1995 and 1996-2000, Hong Kong experienced a compression of disability among people aged 50 and above. Likewise, according to the healthy LE data for 191 countries and Hong Kong from WHOs health assessment of 2000, Law and Yip (2003) concluded that the population of Hong Kong had one of the highest healthy life expectancies at birth in the world. However, a recent study (Chou and Leung 2008) showed that the prevalence of functional limitation decreased from $4.9 \%$ in 1996 to $3 \%$ in 2000 and then increased to $6.9 \%$ in 2004 . This study suggested that, during the period 2000-2004, Hong Kong experienced an expansion of disability among community-dwelling older persons (aged 60+). These diverging results illustrate the importance of both data quality and sources and suggest that different calculation methods can yield results that vary greatly. A more comprehensive picture of Hong Kong's population health status is required; therefore, a range of health dimensions should be examined using survey data.

According to the latest Hong Kong Life Tables, Hong Kong life expectancy at birth increased by more than 16 years between 1971 and 2009, when it reached 79.8 years for men and 86.1 for women, values which are among the highest in the world (HKCSD 2010). Although the gender gap has narrowed in the 1980s and 1990s, it has been widening in the past few years. Hong Kong women tend to live longer than their counterparts by about 6.3 years by 2009 . Longer life without good health is a burden to individuals, families and society. An analysis of population health status is urgently needed in Hong Kong as it will be faced with an ageing population, that too not in distant future (Yip et al. 2010). This article attempts to answer the following questions: Does longer LE imply more healthy years of life or simply more years of chronic morbidity and disability? Will the direction of changes in morbidity and disability curves be in tandem with shifts in
LE? Are Hong Kong women living longer, but with deteriorating health, compared with Hong Kong men?

\section{Methods}

Data sources

To calculate healthy LE, two types of data are needed. Data on mortality enable estimations to be made of LE at different ages. The application of data on the prevalence of two different health indicators (i.e. chronic morbidity and disability) to age- and gender-specific abridged life table enables us to estimate the average number and the proportion of years within a total LE to be lived in each state of health. For this study, gender-specific period abridged life tables for 5-year age intervals, with an open-ended age group at age 85 years, from 1996 to 2008 are obtained from the Hong Kong Census and Statistics Department. The prevalence of chronic morbidity and disability are used to calculate healthy LE in Hong Kong from 1996 to 2008 using the Sullivan method.

Data on the prevalence of chronic morbidity by age and gender are obtained from the Thematic Household Survey (THS) (HKCSD 2000a, 2002, 2003, 2007, 2009a) for five different time periods (September-November 1999, January-May 2001, May-July 2002, November 2005-March 2006 and February-May 2008). The THS has been conducted since 1999 (HKCSD 2000a). Each round of the THS is an independent, territory-wide survey. In each enumerated household, all the household members (excluding foreign domestic helpers) are asked about their health status. Using a sampling design involving non-uniform sampling fractions, a disproportionate stratified systematic sample is drawn for enumeration from a district council constituency area. Some 10,000 community-based households within the enumerated sample are successfully approached, constituting a response rate of $77.5 \%$ (CI 99\%: 76.8-78.2). The methodological approaches adopted by the GHS and the THS surveys remain the same.

The chronic morbidity data cover diseases that require long-term follow-up by doctors, such as hypertension, diabetes mellitus, high cholesterol, heart diseases (i.e. coronary heart disease, heart failure, abnormal palpitation, rheumatic heart disease and angina pectoris), stroke, arthritis (including spurs and rheumatoid arthritis), eye diseases (including cataracts, glaucoma and failing eyesight), apoplexy (including ruptures), gastric diseases (including ulcers of alimentary canal and duodenal ulcers), cancer (in all parts of the body), tracheitis (including chronic bronchitis, pulmonary emphysema and asthma), nephralgia, gout (high uric acid), Parkinson's disease, old age depression, senile dementia, and other chronic 
diseases. The prevalence of chronic morbidity is assessed using the following questions from the various cross-sectional surveys (the Cantonese version is available upon request):

From September to November 1999:

Do you have any diseases that require long-term follow-up by doctors? Yes/No

From January to May 2001:

Do you have any diseases that require long-term follow-up by doctors? Yes/No

From May to July 2002:

Have you ever been diagnosed by a doctor as suffering from the following chronic/long-term diseases? (Show a card) Yes/No

From November 2005 to March 2006:

Have you been diagnosed by a medical doctor as having any of the following chronic or long-term diseases which require long-term follow-up? (Show a card) $\mathrm{Yes} / \mathrm{No}$

From February to May 2008:

Have you ever been told by a Western medicine practitioner that you have the following chronic health conditions? (Show a card) Yes/No

As shown above, there are some variations in the wordings among the different surveys. In the 2002, 2005/ 2006 and 2008 surveys, the participants were shown a card which included different kinds of chronic diseases that are stated in the previous paragraph. Although it appears that the chronic morbidity questions in the five different survey periods have some similarity (such as whether diseases required long-term follow-up by doctors or diagnosed by a doctor or told by a Western medicine practitioner), caution should be taken when the trends in chronic morbidity are interpreted.

To ascertain the age- and gender-specific prevalence of disability among Hong Kong residents, we have used four independent cross-sectional surveys conducted in 1996, 2000, 2004 and 2008. The samples for these surveys were representative samples of Hong Kong community-dwelling older adults aged 60 years and above. The 1996 survey was conducted by the University of Hong Kong (Chou and Leung 2008); the rest of the data come from the General Household Survey (GHS) and the Thematic Household Survey (THS) covering the periods July-September 2000, June-August 2004 and June-August 2008 (HKCSD 2000b, 2005, 2009b). The disability data cover six ADL limitations for people aged 60 and over who reside in a domestic household: eating, getting in or out of a bed or seat, getting around inside, dressing, bathing and using the toilet (the Cantonese version is available upon request).
Participants were asked to indicate whether they were capable of doing these tasks independently, although the specific responses provided were slightly different in the four surveys. For the three ADL items of eating, dressing, and toileting, three response options (independently, need help from others, and depend on others) were provided in the 1996 and 2000 surveys, whereas four options (independently, need a little help, need some help, and depend on others) were given in the 2004 and 2008 surveys. For getting in or out of bed or seat and getting around inside, four options (independently, need a little help, need some help, and depend on others) were provided in all four surveys. For bathing only two options (independently and depend on others) were presented in the 1996 and 2000 surveys, whereas four options (independently, need a little help, need some help, and depend on others) were provided in the 2004 and 2008 surveys. In the 2000, 2004 and 2008 surveys, the ability of older people to perform ADL was assessed by counting the number of ADL that they are unable to perform independently and then classifying their physical condition into one of the four levels shown below. The prevalence of disability is determined by the number of people with a physical impairment level of 2 or above, but this four-level assessment was not used in the 1996 survey.

\begin{tabular}{ll}
\hline $\begin{array}{l}\text { Physical } \\
\text { impairment }\end{array}$ & $\begin{array}{l}\text { Number of ADL that could not } \\
\text { be performed independently }\end{array}$ \\
\hline Level 1 & 0 \\
Level 2 & $1-2$ \\
Level 3 & $3-4$ \\
Level 4 & $5-6$ \\
\hline
\end{tabular}

In the present study, disability in ADL is defined as being unable to perform at least one of six ADL activities independently. All options except 'independently' were recoded to indicate inability to perform the task independently.

\section{Annual changes}

To assess the combined effect of changes in the population age structure and the different health dimensions in Hong Kong, we first calculate the average annual rate of change in chronic morbidity and disability by age and gender through logistic regression analyses. Using this method, we fit a logit form of the rates with the years within the time period to explain their statistical relationship with a linear equation. 
Intrapolation and extrapolation

Since we only have four time points (i.e. 1996, 2000, 2004 and 2008) for disability data and chronic morbidity data for five time points (i.e. 1999, 2001, 2002, 2005/2006 and 2008), we intrapolate the whole time series from 1996 to 2008 for disability data using the intercept and slope from the logistic regression model and extrapolate backwards for 3 years (i.e. 1996, 1997 and 1998) to obtain the whole series of chronic morbidity data.

\section{Sullivan method}

To compute healthy LE and determine the number of years and the proportion of life lived in the two different health dimensions (chronic morbidity and disability), we use the method devised by Sullivan (1971). This method divides total LE into the different health states based on the prevalence of different health conditions at a single point in time. The prevalence rates are used to calculate the person-years of life lived in a specific health condition for the age intervals of the population in the life tables. The person-years of health for each age interval are summed up from age $\mathrm{x}$ onwards to the end of the table to obtain the total number of person-years that are chronic morbidity free and disability free. For instance, chronic morbidity-free life expectancy (CMFLE) values can be obtained by dividing the total number of chronic morbidity-free person-years at each age by the number of survivors in that age group from the basic period life table. This method reflects the current health condition, adjusted for age and mortality levels, of a real population (Jagger et al. 2006). Further details on how to calculate health expectancy using the Sullivan method can be found in Euro-REVES: A Practical Guide (Jagger et al. 2007). Sullivan's estimator is considered to be unbiased and consistent (Imai and Soneji 2007). Therefore, in this study, we compute the expected number of years lived free of chronic morbidity and disability and its proportion in relation to lifetime from 1996 to 2008 to determine whether an 'absolute' or 'relative' expansion or compression of chronic morbidity and disability is occurring in terms of the change in life expectancy. Twenty-four abridged life tables are constructed using the Sullivan method and an open-ended age group $(80+)$ is set into each life table.

To estimate the yearly change in LE, CMFLE and DFLE, each of these indicators is regressed on year using a separate weighted linear regression (with $P$ value). The regressions for each age group are stratified by gender (Van Oyen et al. 2008). The 95\% confidence intervals for the predicted values of LE, CMFLE and DFLE are estimated by using SPSS software version 17.0.

\section{Results}

The overall prevalence of chronic morbidity among men aged 60 and above increased greatly, by 20.8 percentage points, from $40.6 \%$ in 1999 to $61.4 \%$ in 2008 . The overall prevalence of chronic morbidity among women aged 60 and above also increased considerably, by 16 percentage points, from $47.5 \%$ in 1999 to $63.5 \%$ in 2008 , as shown in Fig. 1.

Table 1 shows the annual changes in the prevalence of chronic morbidity by age groups (i.e. 60-64, 65-69, 70-74, 75-79 and 80+) and gender from 1999 to 2008. Logistic regression analyses demonstrated that the rate of increase was most substantial among men aged 80 and over, reaching $19 \%$ per annum. The annual change rates of chronic morbidity were always higher among men except in the 60-64 age group, where there was an annual change rate of $7.2 \%$ for women versus $6.1 \%$ for men.

Figure 2 shows the overall prevalence of disability in the 60 and over age group. From 1996 to 2000, the overall prevalence of disability in this age group declined by nearly 1.1 percentage points, from $4.0 \%$ in 1996 to $2.9 \%$ in 2000 for both genders. For men, there was a moderate increase of 2.3 percentage points in the rate, from $3 \%$ in 1996 to $5.3 \%$ in 2004; the rate then stayed at 5.1\% in 2008 . With regard to women, there was a relatively stronger increase of 2.8 percentage points, from $4.9 \%$ in 1996 to $7.7 \%$ in 2004 ; then, the rate reached its highest level of $8.6 \%$ in 2008 .

Table 2 presents the annual change rates of disability by age groups and gender from 1996 to 2008. For the age groups 70-74 and 75-79, Hong Kong women tended to have higher annual growth rates than men. For the other

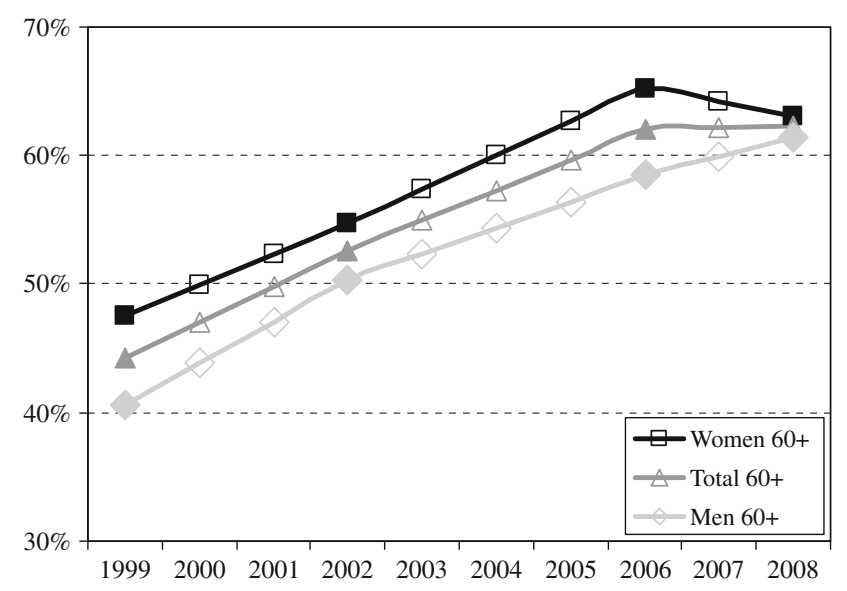

Fig. 1 The prevalence of chronic morbidity in Hong Kong SAR by gender for those aged 60 and above, 1999-2008. Four time points of actual chronic morbidity rates are shown in 1999, 2002, 2005/2006 and 2008. For the year 2002, we obtain the average of prevalence of chronic morbidity of 2001 and 2002 
Table 1 The annual change in rates of chronic morbidity in Hong Kong SAR by age groups and gender, 1999-2008

\begin{tabular}{llll}
\hline & Men & Women & Total \\
\hline $60-64$ & 0.061 & 0.072 & 0.067 \\
$65-69$ & 0.107 & 0.077 & 0.092 \\
$70-74$ & 0.095 & 0.090 & 0.091 \\
$75-79$ & 0.098 & 0.095 & 0.097 \\
$80+$ & 0.191 & 0.153 & 0.167 \\
$60+$ & 0.093 & 0.082 & 0.087 \\
\hline
\end{tabular}

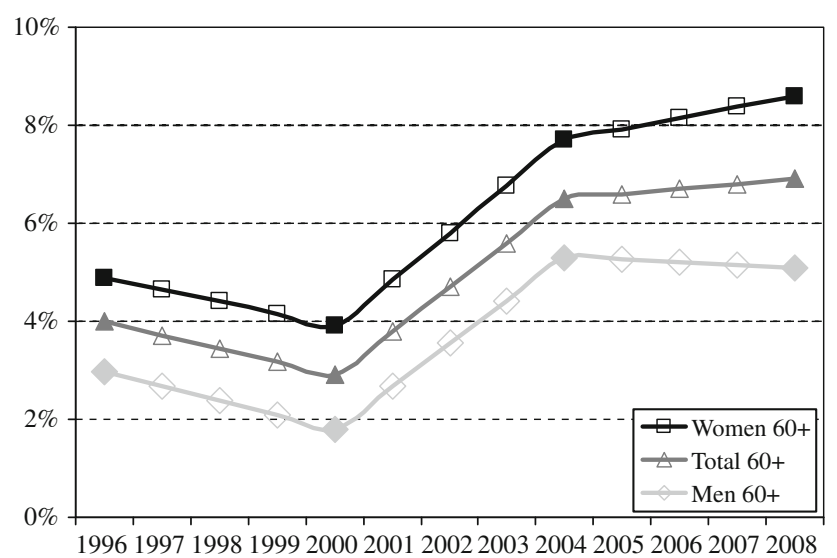

Fig. 2 The prevalence of disability in Hong Kong SAR by gender for those aged 60 and above, 1996-2008. Four time points of actual disability rates are shown in 1996, 2000, 2004 and 2008

Table 2 The annual change in rates of disability in Hong Kong SAR by age groups and gender, 1996-2008

\begin{tabular}{llll}
\hline & Men & Women & Total \\
\hline $60-64$ & 0.150 & 0.013 & 0.051 \\
$65-69$ & 0.127 & 0.004 & 0.061 \\
$70-74$ & 0.060 & 0.064 & 0.061 \\
$75-79$ & 0.001 & 0.082 & 0.048 \\
$80+$ & 0.076 & 0.071 & 0.071 \\
$60+$ & 0.086 & 0.073 & 0.076 \\
\hline
\end{tabular}

age groups, the logistic regression analyses show that the rate of increase was most substantial among men in the 60-64 and 65-69 age groups, the rate reaching almost $12.7-15.0 \%$ per annum.

Healthy life expectancies

The presentation of the results is stratified by gender and different ages (i.e. at ages 60, 65, 70, 75 and 80). Figure 3 presents the absolute differences in LE, CMFLE and DFLE between the first (1996) and last (2008) year. Between 1996 and 2008, the total LE at age 60 for men increased by 1.75 years. At the most advanced age (i.e. age 80 ), the increase in the LE was 0.71 years, which was less than that for the younger ages (i.e. ages 60, 65, 70 and 75). Among Hong Kong women, for those aged 60, there was a 2.20 years increase in LE, which was about 0.45 years greater than the figure for men in the same age group (Fig. 3). With regard to women in the older ages (i.e. ages 75 and 80), the increase in LE diminished with age, but this increase was still larger than that for men. Our results show that although LE has increased over time for all age groups, CMFLE declined remarkably, and the increase in DFLE was not greater than the LE gain, suggesting an absolute expansion of chronic morbidity and disability between 1996 and 2008.

In Tables 3 and 4, for men and women respectively, all of the estimates (with $95 \%$ confidence intervals) for the four time points (i.e. 1996, 2001, 2006 and 2008) and for each of the health expectancy indicators (i.e. CMFLE and DFLE) are given together with an estimate of the yearly change. In Table 3 , the results show a strong expansion of chronic morbidity, as CMFLE declined greatly for men at ages 60, 65, 70 and 75. The yearly changes during the period 1996-2008 were all statistically significant $(P \leq 0.005)$. There were both an absolute and a relative expansion in both the health domains: (1) the increase in LE was greater than both the increases in DFLE, whereas there was a decrease in CMFLE, and (2) the proportion of life without chronic morbidity declined substantially between 1996 and 2008.

Likewise, Hong Kong men aged 80 and above experienced both a strong absolute and a relative expansion in the two health domains: (1) there was an increase in LE (0.059 per year) versus a decrease in both CMFLE $(-0.428$ per year) and DFLE ( -0.018 per year) and (2) the proportion of life without chronic morbidity decreased dramatically, from $90.3 \%$ in 1996 to $25.6 \%$ in 2008 . The proportion of life free of disability also declined, from $89.4 \%$ in 1996 to $83.1 \%$ in 2008 (Table 3).

Table 4 shows the LE, CMFLE and DFLE among Hong Kong women from 1996 to 2008. For Hong Kong women aged 60 and 65, there were both an absolute and a relative expansion in the two health domains: (1) the increase in LE was greater than the increase in DFLE whereas there was a decrease in CMFLE, and (2) the proportion of life without chronic morbidity declined significantly (Table 4). Although DFLE increased for these two age groups, these increases were much smaller than the increase in LE.

With regard to women in the older ages (i.e. ages 70, 75 and 80), the increase in LE diminished with age, but this increase was still larger than that for men. Hong Kong women in these older age groups experienced both an absolute and a relative expansion in the two health domains: (1) there was an increase in LE versus a decrease in both CMFLE and DFLE, and (2) the proportion of life 

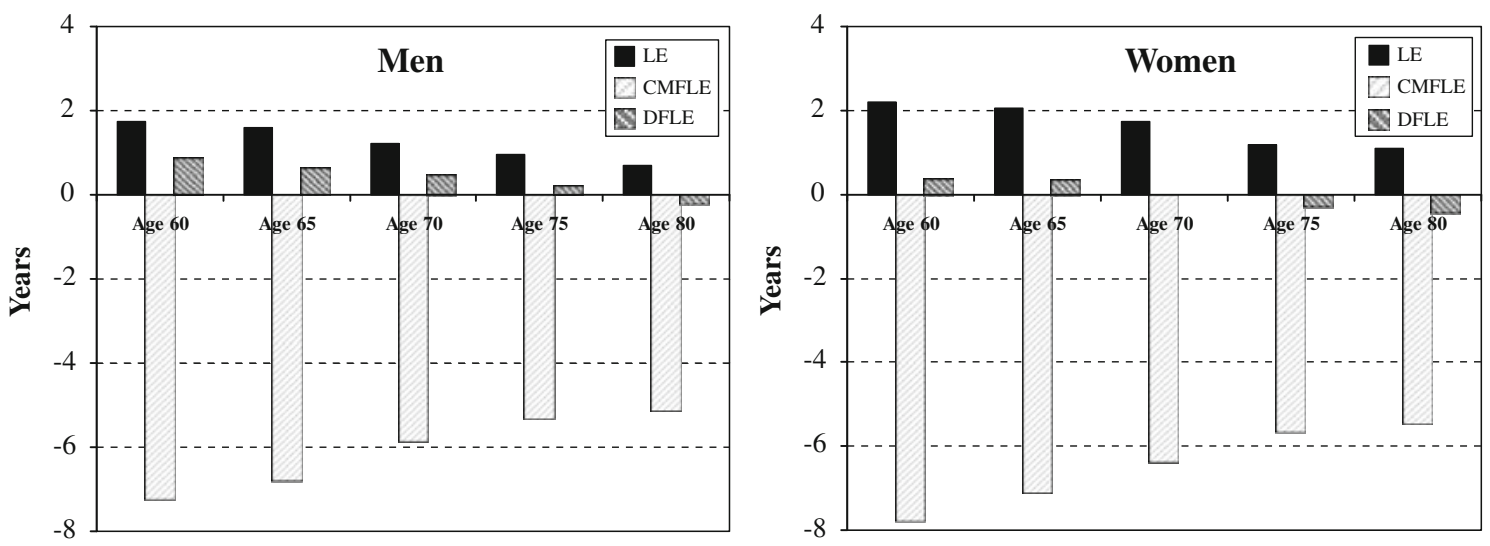

Fig. 3 Change in total life expectancy (LE), health expectancy indicators based on chronic morbidity-free life expectancy (CMFLE), and disability-free life expectancy (DFLE) at ages 60, 65, 70, 75 and 80 by gender, Hong Kong SAR, 1996-2008

without chronic morbidity declined dramatically. Compared to men, these women tended to have a lower proportion of life free of chronic morbidity and disability (Tables 3, 4). For the advanced age group (aged 80), the yearly change for women was -0.454 , which reflects that, for them, CMFLE declined by nearly 5 months per year. By 2008, both the CMFLE and the DFLE of Hong Kong women aged 80 had decreased far more than that of their male counterparts, and a smaller proportion of their lives was free of chronic morbidity and disability.

\section{Discussion}

In this article, we focused on the evolution of population health in terms of two health domains (chronic morbidity and disability) in relation to increase in LE. Forty years ago, Fries (1980) proposed the assumption of a fixed length of human life with the compression of morbidity hypothesis. As observed previously, Hong Kong SAR experienced a compression of mortality in which the majority of people today could survive to the age of 80 , whereas 40 years ago less than half of the people could do so (Cheung 2003; Cheung et al. 2005a, b). The lengthening of life, however, does not mean that Hong Kong people have years of life with better health. Worsening health and longer life mean that more long-term health-care and medical services will be needed in the future.

Our article sheds new light on the evolution of population health in Hong Kong using survey data and the Sullivan method. We aimed to gain more insight into the question of whether longer life is associated, both absolutely and relatively, with an increase in years of good health or years of poor health. We especially sought an answer to the question of whether, compared to men, Hong Kong women are living longer, but in worsening health, and tending to have more years of life with disability. Our results indicate that Hong Kong women tend to outlive Hong Kong men and that they live more years of life with more chronic morbidity and disability. The expansion of chronic morbidity and disability among older adults between 1996 and 2008 suggests that we are experiencing 'the failures of success'.

Nevertheless, our study has some shortcomings. We only focused on the health status of senior adults aged 60 and above, although several age groups within this broad category were used in the study. More research on the health status of different adult age groups, such as the 'soon-to-be-old' (50-54) and the 'young-old' (55-59), is needed. Owing to nature of the available data, we had a broad 80 and over age group in which we unable to monitor the changes of the health status for those aged 80, 85, 90, 95, and so on. An examination of the health status of the oldest-old (80-99) and centenarians (100+) is of prime importance as their health status could differ greatly from that of other younger older age groups and their needs will vary from those of the soon-to-be-old, the young-old and the old-old.

In addition, as observed, there has been a great increase in both the number, from 428,600 in 1999 to 731,800 in 2008, and the proportion, from $42 \%$ in 1999 to $65.4 \%$ in 2008 , of people in the 60 and over age group with chronic morbidity. Compared with experiences overseas, this increase seems astonishingly large. Some overseas studies already pointed out that analysis of changes in morbidity and disability prevalence can be sensitive to the intrainterval estimates (Crimmins et al. 1997) and change in question wording (Freedman et al. 2007). Although the overall estimated annual trend in CMFLE is statistically significant and the five time-point cross-sectional surveys were all conducted by the Thematic Household Survey (THS), the results should be interpreted cautiously because 


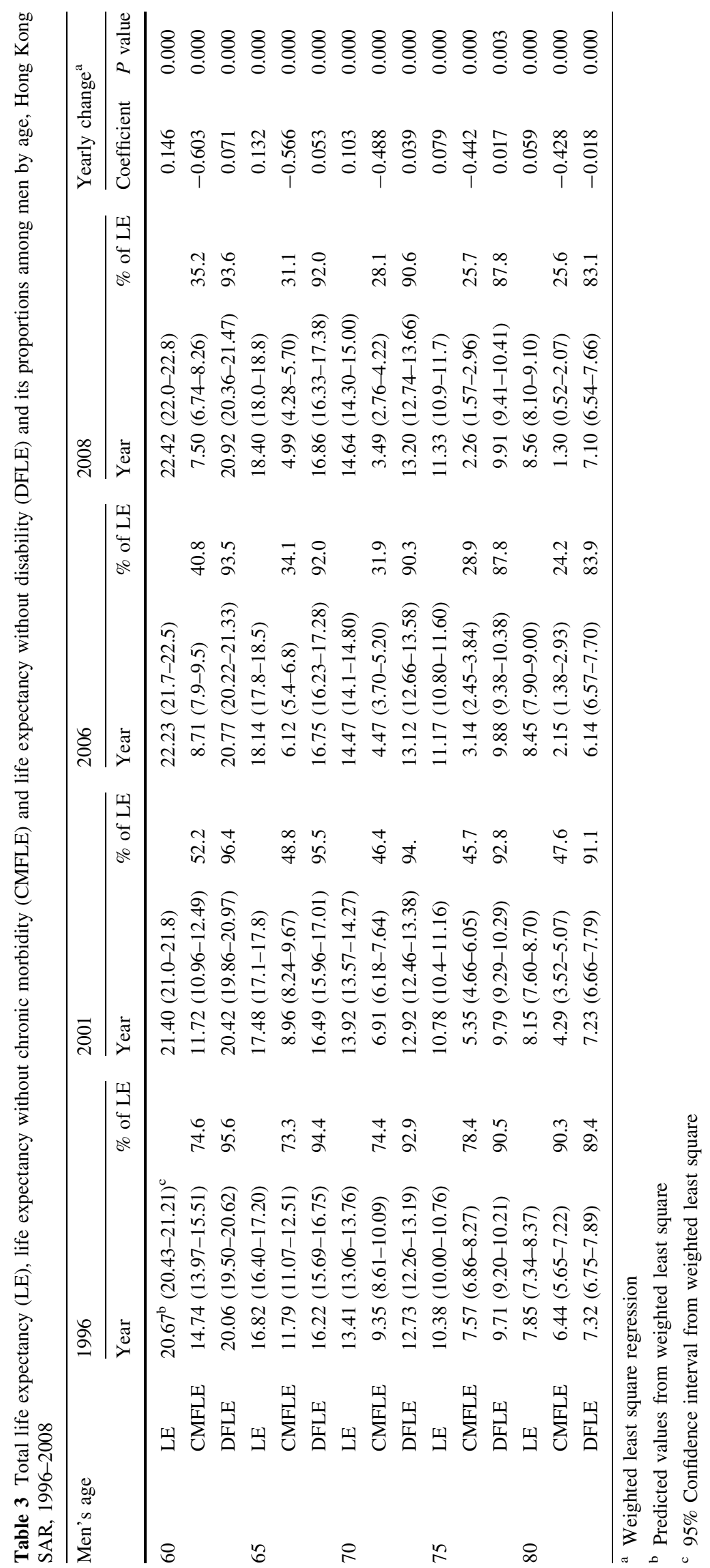




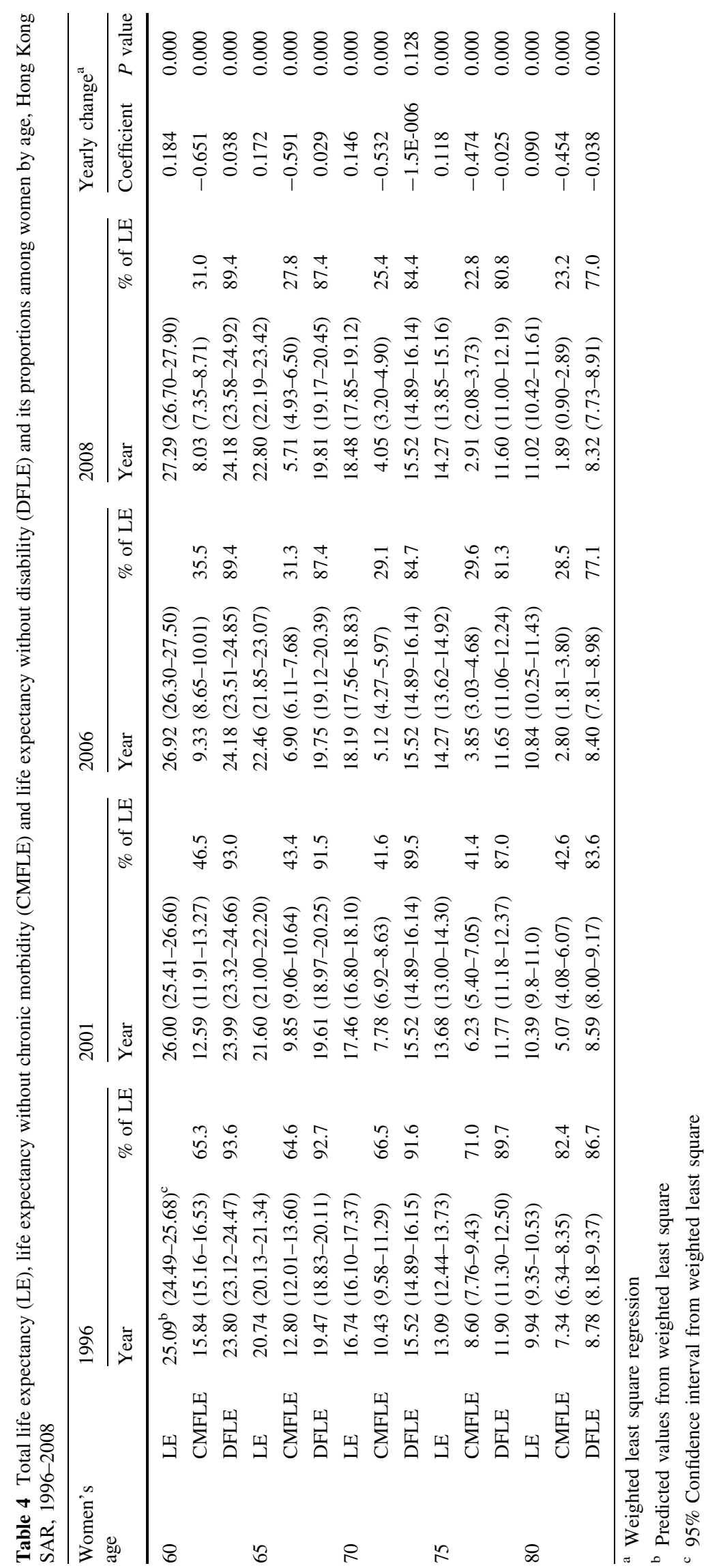


there are some variations in wording and the mode of data collection (such as showing a card about diseases' names to the participants in the 2002, 2005/2006 and 2008 surveys may improve the reporting situation but not in the previous two surveys in 1999 and 2001).

Apart from the wording of the question and the mode of data collection, it is well known that response categories may affect response distributions and lead to incorrect conclusions (Ekholm and Brønnum-Hansen 2009). Although the questions of ADL were nearly identical for the four cross-sectional surveys, there were three response options in the 1996 and 2000 surveys for the three ADL items of eating, dressing, and toileting and four options in the 2004 and 2008 surveys. Likewise, for bathing there were two options in the 1996 and 2000 surveys, whereas four levels were provided in the 2004 and 2008 surveys. Therefore, cautions should be held when the results for the overall trend of disability are interpreted. In Fig. 2, the shift in levels of disability between 1996-2000 and 2004-2008 might be explained by the fact that the major changes in the response options were made between these two periods of which different response categories were used.

Moreover, the data are subject to both sampling error and non-sampling error. The estimates contained in the THS and STR were based on the information obtained from a particular sample, which was only one of many possible samples that could have been selected using the same sample design. In addition, the surveys covered only community-based Hong Kong residents (HKCSD 2005, 2007, 2009a, b). Future research should also examine the changes in the health status of an institutional population.

As highlighted by Katz and his associates (1963), the index of ADL is a survey instrument, an objective guide to the course of chronic illness and a tool for studying the ageing process. The index of feeding, continence, and transfer is recognized as reflecting the organized locomotor and neurological aspects of simple vegetative functions which can be considered as the most basic and least complex activities. On the other hand, bathing, dressing and going to the toilet require organized locomotor and neurological functioning, but these activities are prominently influenced by cultural forces and learning which can be seen as the most complex and least basic activities. Usually, as an older person's health deteriorates, they begin to experience functional loss in one of these daily activities. If a person loses their abilities in relation to the most basic and least complex activities, then this will suggest that they require a higher level and a greater amount of assistance from their family or a carer than someone who is limited in terms of the most complex and least basic activities. As our study used just one level of disability (i.e. whether the respondents had one or more ADL limitations (level 2 and above)), it could not show an orderly pattern of the severity levels of functional loss. In future studies, it is of prime importance that we should look into these two separate spheres (i.e. most basic and least complex activities vs. most complex and least basic activities), as this will provide a better understanding of the different levels and amounts of long-term personal assistance and health care that older people require. Another disability indicator, the instrumental activity of daily living (IADL) proposed by Lawton and Brody (1969), could also be used to examine the trends in activity restrictions related to daily management at home.

Compared to the time series available in many Western countries, the period of observation in this study (1996-2008) was rather short. The study therefore has only five observation points for chronic morbidity and four time points for disability. The intrapolation and linear trend estimates of yearly changes could provide alternative estimates for monitoring the evolution of health status, but we should be cautious in interpreting the trends observed.

The older population of Hong Kong has grown at a rapid rate. The number of older people aged 60 and above in Hong Kong is set to increase in the near future, from about 1.1 million in 2006 ( $16 \%$ of the total population) to 2.7 million in 2036 (about $32 \%$ of the total population), and the proportion of older people aged 60 and above will double, from 1 in 8 in 2006 to 1 in 4 by 2036. One of the greatest challenges of the shift in population towards an older age spectrum is not simply how large the older population is and how long older people live, but also how long they will live in good health (i.e. having active and independent daily lives). The oldest-old (80+) age group will also grow rapidly, from about 205,000 in 2006 (3\% of the total population) to 667,000 in 2036 (7.8\% of the total population). This group will grow faster than any other age group, which is especially significant because (1) this group requires more intensive health services and social care than the younger-old and (2) very little is known about their needs and ways to improve their health and wellbeing.

Indeed, according to the Annual Digest of Statistics (HKCSD 2008), the health expenditure in total recurrent public expenditure has increased by 4.1 billion, from 23.9 billion Hong Kong dollars (10.2\% of the total expenditure) in $1997 / 98$ to 28 billion Hong Kong dollars (11.9\% of the total expenditure) in 2007/08. As Hong Kong women tend to suffer from a 'double disadvantage', namely longer life with more chronic morbidity and disability than men, the Hong Kong government should take a leading role in promoting 'the successes of success'. For example, the government could encourage people to work fewer hours per day but for more years, and could either postpone retirement or maintain a flexible retirement scheme so that those older adults who are cognitively and physically intact 
can continue to work. Some chronic conditions are highly related to behavioural patterns (e.g. consuming high levels of red meats and engaging in risky behaviours). To minimize the health and mortality paradox between men and women, preventive measures should be introduced to (1) address the problems of risky behaviours and behaviourrelated diseases (e.g. cancer: smoking; liver disease: alcoholism) and (2) minimize premature and preventable deaths (i.e. suicide, accidents) among younger age groups (Vaupel 2010). Since January 2007, smoking has been prohibited in public areas in Hong Kong, but it may take several years to see the effects of this measure and whether it will have an impact on the rate of chronic morbidity.

\section{Conclusions}

The recent increase in LE in Hong Kong among older adults has been accompanied by a worsening health status, most significantly for women. The use of two health domains for different age groups and genders among the older population in Hong Kong reveals this differentiation in the ageing and disability process. Our results show that Hong Kong women tend to outlive Hong Kong men but are also more likely to suffer from a 'double disadvantage', namely longer years of life with more chronic morbidity and disability than men. Future research agendas should focus not only continuous monitoring through cross-sectional surveys, but also on launching a detailed longitudinal study of the health status of the Hong Kong population, including representative samples of those who are the oldest-old and centenarians.

Acknowledgments The earlier version of this research paper was presented at 21st REVES 2009: Reducing gaps in health expectancy, May 27-29, 2009 in Copenhagen, Denmark. The authors would like to thank the Croucher Foundation for the travel grant support and the REVES participants for the useful comments received. The authors are also grateful to the anonymous reviewers and the editors for their helpful and constructive comments on the manuscript. The work described in this paper was substantially supported by a grant from the Small Project Funding, administered by the University Research Committee of the University of Hong Kong (Project Code. 200907176158, Project Title: Hong Kong Health Expectancy and Disease Burden Study) and a research grant of Public Policy Research of the Research Grants Council.

Open Access This article is distributed under the terms of the Creative Commons Attribution Noncommercial License which permits any noncommercial use, distribution, and reproduction in any medium, provided the original author(s) and source are credited.

\section{References}

Ahacic K, Kareholt I, Thorslund M, Parker MG (2007) Relationships between symptoms, physical capacity, activity limitations in 1992 and 2002. Aging Clin Exp Res 19(3):187-193
Brønnum-Hansen H (2005) Health expectancy in Denmark, 1987-2000. Eur J Public Health 15(1):20-25

Cambois E, Clavel A, Romieu I, Robine JM (2008) Trends in disability-free life expectancy at age 65 in France: consistent and diverging patterns according to the underlying disability measure. Eur J Ageing 5(4):287-298

Canudas-Romo V (2008) The modal age at death and the shifting mortality hypothesis. Demogr Res 19(3):1179-1204

Cheung SLK (2003) Scalar expansion and normal longevity in Hong Kong. PhD Thesis, Division of Social Science, The Hong Kong University of Science and Technology

Cheung SLK, Robine JM (2007) Increase in common longevity and the compression of mortality: the case of Japan. Popul Stud 61(1):85-97

Cheung SLK, Tu JCE (2002) Trends in healthy life expectancy: Hong Kong 1981-2000. REVES meeting 2002-aging in emerging countries, Hammamet, Tunisia, 24-26 Apr 2002

Cheung SLK, Robine JM, Tu JCE, Caselli G (2005a) Change in the distribution of normal life durations through the demographic transition: the case of Hong Kong. Unpublished manuscript. INSERM/Demographie et Sante, Montpellier, France

Cheung SLK, Robine JM, Tu JCE, Caselli G (2005b) Three dimension of the survival curve: horizontalization, verticalization, and longevity extension. Demography 42(2):243-258

Cheung SLK, Robine JM, Caselli G (2008) The use of cohort and period data to analyze change in normal longevity in low mortality countries. Genus LXIV(1-2):101-129

Cheung SLK, Robine JM, Marazzi A, Paccaud F (2009) Dissecting compression of mortality in Switzerland, 1876-2005. Demogr Res 21(19):569-598

Chou KL, Leung J (2008) Disability trends in Hong Kong community-dwelling Chinese older adults: 1996, 2000 and 2004. J Aging Health 20(4):385-404

Crimmins EM, Saito Y (1993) Getting better and getting worse. J Aging Health 5:3-36

Crimmins EM, Saito Y, Reynolds SL (1997) Further evidence on recent trends in the prevalence and incidence of disability among older American from two sources: the LSOA and the NHIS. J Gerontol 52(2):S59-S71

Doblhammer G, Kytir J (2001) Compression or expansion of morbidity? Trends in healthy-life expectancy in the elderly Austrian population between 1978 and 1998. Soc Sci Med 52(3):385-391

Downes J (1950) Cause of illness among males and females. Milbank Meml Fund Q 28(4):407-428

Ekholm O, Brønnum-Hansen H (2009) Cross-national comparisons of non-harmonized indicators may lead to more confusion than clarification. Scand J Public Health 0:1-3

Freedman VA, Schoeni RF, Martin LG, Cornman JC (2007) Chronic conditions and the decline in late-life disability. Demography 44(3):459-477

Fries JF (1980) Aging, natural death and the compression of morbidity. N Engl J Med 303:130-135

Gruenberg E (1977) The failures of success. Milbank Meml Fund Q 55(1):3-24

Hong Kong Census and Statistics Department (2000a) Health status of Hong Kong residents, doctor consultation, hospitalization. Thematic Household Survey Report No. 3. HKSAR

Hong Kong Census and Statistics Department (2000b) Socio-demographic, health and economic profiles of elderly people and soon-to-be old people. Special Topics Report No. 27. HKSAR

Hong Kong Census and Statistics Department (2002) Health status of Hong Kong residents, doctor consultation, hospitalization. Thematic Household Survey Report No. 8. HKSAR

Hong Kong Census and Statistics Department (2003) Health status of Hong Kong residents, doctor consultation, hospitalization. Thematic Household Survey Report No. 12. HKSAR 
Hong Kong Census and Statistics Department (2005) Socio-demographic profile, health status and long-term care needs of older persons. Thematic Household Survey Report No. 21. HKSAR

Hong Kong Census and Statistics Department (2007) Health status of Hong Kong residents, doctor consultation, hospitalization. Thematic Household Survey Report No. 30. HKSAR

Hong Kong Census and Statistics Department (2008) Hong Kong annual digest of statistics. HKSAR

Hong Kong Census and Statistics Department (2009a) Health status of Hong Kong residents, doctor consultation, hospitalization. Thematic Household Survey Report No. 41. HKSAR

Hong Kong Census and Statistics Department (2009b) Socio-demographic profile, health status and self-care capability of older persons. Thematic Household Survey Report No. 40. HKSAR

Hong Kong Census and Statistics Department (2010) Hong Kong life tables 2004-2039. HKSAR

Imai K, Soneji S (2007) On the estimation of disability-free life expectancy: Sullivan's method and its extension. J Am Stat Assoc 102(480):1199-1211

Jackson EH (1950) Morbidity among males and females at specific ages: eastern health district of Baltimore. Milbank Meml Fund Q 28:429-448

Jagger C, Cox B, Le Roy S, The EHEMU Group (2006) Health expectancy calculation by the Sullivan method, 3rd edn. EHEMU Technical Report (downloaded from http://www. ehemu.eu/; training material and calculation guide)

Jagger C, Cox B, Le Roy S, The EHEMU Group (2007). Health expectancy calculation by the Sullivan method: a practical guide. http://www.ehemu.eu/pdf/Sullivan_guide_final_jun2007.pdf. Accessed June 2007

Jeune B, Brønnum-Hansen H (2008) Trends in health expectancy at age 65 for various health indicators, 1987-2005, Denmark. Eur J Ageing 5(4):279-285

Kannisto V (2001) Mode and dispersion of the length of life. Popul: An Engl Sel 13(1):159-171

Katz S, Ford AB, Moskowitz RW, Jackson BA, Jaffe MW (1963) Studies of illness in the aged. The index of ADL: a standardized measure of biological and psychosocial function. J Am Med Assoc 185:914-919

Kramer M (1980) The rising pandemic of mental disorders and associated chronic diseases and disabilities. Acta Psychiatr Scand 62(Suppl 285):382-397

Lafortune G, Balestat G (2007) Trends in severe disability among elderly people: assessing the evidence in 12 OECD countries and future implications. OECD Health Working papers No. 26. OECD. Assessed June 2009

Laslett P (1995) Necessary knowledge: age and aging in the societies of the past. In Kertzer DI, Laslett P (eds) Aging in the past: demography, society and old age, Chap. 1. University of California Press, Berkeley, CA, pp 3-77

Law CK, Yip PSF (2003) Healthy life expectancy in Hong Kong Special Administrative Region of China. Bull World Health Organ 81:43-47

Lawton M, Brody E (1969) Assessment of older people: selfmaintenance and instrumental activities of daily living. Gerontologist 9:179-186

Liu JF, Chan G, Song XM, Chi I, Zheng XY (2009) Trends in disability-free life expectancy among Chinese older adults. J Aging Health 21(2):266-285

Manton KG (1982) Changing concepts of morbidity and mortality in the elderly population. Meml Fund Q 60(2):183-244

Manton KG, Stallard E (1996) Longevity in the United States: age and gender-specific evidence on life span limits from mortality patterns 1960-1990. J Gerontol Biol Sci 51A(5):B362-B375
Martel S, Bourbeau R (2003) Compression de la mortalité et rectangularisation de la courbe de survie au Québec au cours du XX ${ }^{\mathrm{e}}$ Siècle. Cah Qué de Démogr 32(1):43-75

Nusselder W (2003) Compression of morbidity. In: Robine JM, Jagger C, Mathers C, Crimmins E, Suzman R (eds) Determining health expectancies. Wiley, Chichester, pp 35-58

Nusselder WJ, Mackenbach JP (1996) Rectangularization of the survival curve in the Netherlands, 1950-1992. Gerontologist 36(6):773-782

Nusselder WJ, Looman CWN, Mackenbach JP (2006) The level and time course of disability: trajectories of disability in adults and young elderly. Disabil Rehabil 28:1015-1026

Ofstedal MB, Zimmer S, Cruz G, Chan A, Chuang YL (2004) Selfassessed health expectancy among older adults: a comparison of six Asian settings. Hallym Int J Aging 6(2):95-117

Olshansky SJ, Rudberg MA, Carnes BA, Cassell CK, Brody JA (1991) Trading off longer life for worsening health: the expansion of morbidity hypothesis. J Aging Health 3(2):194-216

Paccaud F, Pinto CS, Marazzi A, Mili J (1998) Age at death and rectangularization of survival curve: trends in Switzerland, 1969-1994. J Epidemiol Community Health 52:412-415

Parker MG, Thorslund M (2007) Health trends in the elderly population: getting better and getting worse. Gerontologist 47(2):150-158

Pelletier F, Legare J, Bourbeau R (1997) Mortality in Quebec during the nineteenth century: from the state to the cities. Popul Stud 51:93-103

Perenboom RJM (2004) Health expectancies in the Netherlands. PhD dissertation, University of Amsterdam. http://dare.uva.nl/ document $/ 74094$

Robine JM (2001) A new biodemographic model to explain the trajectory of mortality. Exp Gerontol 36:899-914

Robine JM (2002) A new health expectancy classification system. In: Murray CJL, Salmon JA, Mathers CD, Lopez AD (eds) Summary measures of population health. Concepts, ethics measurement and applications. WHO, Geneva, pp 205-211

Robine JM (2006) Trends in population health. Aging Clin Exp Res 18(5):349-351

Robine JM, Mathers CD (1993) Measuring the compression or expansion of morbidity through changes in health expectancy. In: Robine JM, Mathers CD, Bone MR, Romieu I (eds) Calculation of health expectancies: harmonization, consensus achieved and future perspectives. John Libbey Eurotext, Montrouge, pp 269-286

Robine JM, Michel JP (2004) Looking forward to a general theory on population aging. J Gerontol A Biol Sci Med Sci 59(6):M590M597

Robine JM, Brouard N, Colvez A (1987) Les indicateur d'espérance de vie sans incapacité (EVSI). Des indicateurs globaux de l'état de santé des populations. Rev Epidémiol Santé Publique 35:206-224

Robine JM, Cheung SLK, Thatcher AR, Horiuchi S (2006) What can be learnt by studying the adult modal age at death? Paper presented at Population Association of America annual meeting, Los Angeles, CA, USA, 30 Mar-1 Apr 2006

Robine JM, Cheung SLK, Horiuchi S, Thatcher AR (2008) Is the compression of morbidity a universal phenomenon? Society of Actuary, Living to 100 Symposium, 7-9 Jan 2008

Robine JM, Saito Y, Jagger C (2009) The relationship between longevity and healthy life expectancy. Qual Ageing 10(2):5-14

Rothenberg R, Lentzner HR, Parker RA (1991) Population aging patterns: the expansion of mortality. J Gerontol Soc Sci 46(2):S66-S70

Sanders BS (1964) Measuring community health levels. AJPH 54(7):1063-1070 
Schoeni R, Liang J, Bennett J, Sugisawa H, Fukaya T, Kobayashi E (2006) Trends in old-age functioning and disability in Japan, 1993-2002. Popul Stud 60(1):39-53

Sullivan DF (1971) A single index of mortality and morbidity. HSMHA Health Rep 86(4):347-354

Thatcher AR, Cheung SLK, Horiuchi S, Robine J-M (2010) The compression of deaths above the mode. Demogr Res 22(17):505-538

The Staff of the Benjamin Rose Hospital (1959) Multidisciplinary studies of illness in aged persons II. A new classification of functional status in activities of daily living. J Chronic Dis 9:55-62

The Staff of the Benjamin Rose Hospital (1960) Multidisciplinary studies of illness inaged persons III. Prognostic index in fracture of the hip. J Chronic Dis 11:445-455

The Staff of the Benjamin Rose Hospital (1961) Multidisciplinary studies of illness in aged persons V. A new classification of socioeconomic functioning of the aged. $\mathrm{J}$ Chronic Dis $13: 453-454$

The Staff of the Benjamin Rose Hospital (1962) Multidisciplinary studies of illness in aged persons VI. Comparison study of rehabilitated and nonrehabilitated patients with fracture of the hip. J Chronic Dis 15:979-984

Van Oyen H, Cox B, Demarest S, Deboosere P, Lorant V (2008) Trends in health expectancy indicators in older adult population in Belgium between 1997 and 2004. Eur J Ageing 5:137-146

Vaupel WJ (2010) Biodemography of human ageing. Nature 464:536-542

Verbrugge LM (1984) Longer life but worsening health? Trends in health and mortality of middle-aged and older person. Milbank Meml Fund Q/Health Soc 27:S128-S147

Wilmoth JR, Horiuchi S (1999) Rectangularization revisited: variability of age at death within human populations. Demography 36(4):475-495

World Health Organization (2001) International classification of functioning, disability and health (ICF). World Health Organization, Geneva

Yip PSF, Cheung SLK, Law CKS, Chi I, Robine JM (2010) The demographic window and economic dependency ratio in Hong Kong SAR. Asian Popul Stud 6(2):241-260

Yong V, Saito Y (2009) Trends in healthy life expectancy in Japan: 1986-2004. Demogr Res 20(19):467-494 